\title{
Negative Symptoms in Schizophrenia: A Review and Clinical Guide for Recognition, Assessment, and Treatment
}

This article was published in the following Dove Press journal: Neuropsychiatric Disease and Treatment

\author{
Christoph U Correll $\mathbb{D}^{1-3}$ \\ Nina R Schooler ${ }^{4}$ \\ 'The Zucker Hillside Hospital, Division of \\ Psychiatry Research, Northwell Health, \\ Glen Oaks, NY, USA; ${ }^{2}$ The Donald and \\ Barbara Zucker School of Medicine at \\ Hofstra/Northwell, Department of \\ Psychiatry and Molecular Medicine, \\ New York, NY, USA; ${ }^{3}$ Charité \\ Universitätsmedizin, Department of \\ Child and Adolescent Psychiatry, Berlin, \\ Germany; ${ }^{4}$ State University of New York, \\ Downstate Medical Center, Brooklyn, \\ NY, USA
}

\begin{abstract}
Schizophrenia is frequently a chronic and disabling disorder, characterized by heterogeneous positive and negative symptom constellations. The objective of this review was to provide information that may be useful for clinicians treating patients with negative symptoms of schizophrenia. Negative symptoms are a core component of schizophrenia that account for a large part of the long-term disability and poor functional outcomes in patients with the disorder. The term negative symptoms describes a lessening or absence of normal behaviors and functions related to motivation and interest, or verbal/emotional expression. The negative symptom domain consists of five key constructs: blunted affect, alogia (reduction in quantity of words spoken), avolition (reduced goal-directed activity due to decreased motivation), asociality, and anhedonia (reduced experience of pleasure). Negative symptoms are common in schizophrenia; up to $60 \%$ of patients may have prominent clinically relevant negative symptoms that require treatment. Negative symptoms can occur at any point in the course of illness, although they are reported as the most common first symptom of schizophrenia. Negative symptoms can be primary symptoms, which are intrinsic to the underlying pathophysiology of schizophrenia, or secondary symptoms that are related to psychiatric or medical comorbidities, adverse effects of treatment, or environmental factors. While secondary negative symptoms can improve as a consequence of treatment to improve symptoms in other domains (ie, positive symptoms, depressive symptoms or extrapyramidal symptoms), primary negative symptoms generally do not respond well to currently available antipsychotic treatment with dopamine $D_{2}$ antagonists or partial $D_{2}$ agonists. Since some patients may lack insight about the presence of negative symptoms, these are generally not the reason that patients seek clinical care, and clinicians should be especially vigilant for their presence. Negative symptoms clearly constitute an unmet medical need in schizophrenia, and new and effective treatments are urgently needed.
\end{abstract}

Keywords: schizophrenia, negative symptoms, prevalence, clinical presentation, diagnosis, treatment

\section{Introduction}

Schizophrenia is frequently a chronic and disabling disorder, characterized by heterogeneous positive and negative symptom constellations. ${ }^{1}$ The distinction between positive and negative symptoms originated in the field of neurology and was later adopted in psychiatry; in schizophrenia, this distinction corresponds to clinical observations and allows the disorder to be described in terms of symptom domains. While positive symptoms reflect an excess or distortion of normal function (eg, delusions, hallucinations, disorganized behavior), negative symptoms refer to a diminution or absence of normal behaviors related to motivation and interest
Correspondence: Christoph U Correll The Zucker Hillside Hospital, Division of Psychiatry Research, 75-59 263rd Street, Glen Oaks, NY I I004, USA

Tel + I 718 470-48I2

Email ccorrell@northwell.edu 
(eg, avolition, anhedonia, asociality) or expression (eg, blunted affect, alogia). Negative symptoms are a core component of schizophrenia and they account for a large part of the long-term morbidity and poor functional outcome in patients with the disorder. ${ }^{2-4}$ Associated with significant deficiencies in motivation, communication, affect, and social functioning, negative symptoms are a multifaceted concept with dimensions that may have different impacts on functional outcomes. ${ }^{5}$

Although positive symptoms are generally effectively managed with available antipsychotic medications, limited treatment options are available for negative symptoms and despite advances in understanding the epidemiology, etiology, biology, and psychopharmacology of schizophrenia, they remain an unmet medical need. ${ }^{6}$ Although numerous articles about negative symptoms of schizophrenia are available in the literature, many are focused on research and contain details that may be less relevant or helpful to clinicians who encounter patients with schizophrenia and negative symptoms in usual clinical care settings. The objective of this narrative review is to provide clinicians with a comprehensive source of information about the diverse attributes of negative symptoms of schizophrenia. This current information about the anatomy, assessment, and management of negative symptoms aims to be useful to clinicians treating patients with this challenging manifestation of schizophrenia.

\section{Methods}

Reference databases were searched to identify articles relevant to our topic. A multistep literature search was undertaken using PubMed and Google Scholar to retrieve articles using the term "negative symptoms schizophrenia." Results were limited to review articles and metaanalyses published in the past 10 years (2009-2019) in an effort to find current information that did not directly report clinical trial results. This search retrieved 7229 entries. We narrowed our results by searching in conjunction with more specific terms, such as definition, assessment, symptom domains, factors, secondary negative symptoms, functional impairment, and treatment. Additionally, reference lists of relevant reviews and primary studies were manually searched to find articles that did not appear in our computerized search. English language articles that were published in peer-reviewed journals were included. The content of the search results was divided into the following sections: Terminology, Course, Prevalence, Burden, Neurobiology, Clinical Presentation, Assessment, Treatment, and Best Clinical Practices.

\section{Results}

\section{Negative Symptom Terminology}

"Negative symptoms" is a general descriptive term used without consideration of the cause, longitudinal stability, or duration of the symptoms. Although some negative symptoms are signs that can be observed by a clinician (eg, affective flattening, alogia), other aspects of behavior, such as social withdrawal or diminished engagement in productive or pleasurable activities, may or may not be associated with negative symptoms. As such, asking patients about their interests, emotions, and motivation adds great value to patient observation during negative symptom assessment. Although various more specific terms are used in the literature to describe the nature and etiology of negative symptoms (eg, deficit, predominant, prominent, persistent) as they pertain to research, there is no consensus definition for any term (Table 1). While some descriptors (eg, prominent versus predominant, enduring/persistent versus nonenduring/nonpersistent) have clinical meaning and implications for treatment, the academically appropriate term may not be as important as appropriately identifying and treating all patients in the clinic who have clinically significant negative symptoms or signs.

Differentiating primary negative symptoms (intrinsic to the underlying pathophysiology of schizophrenia) from secondary negative symptoms (related to other factors) can be challenging. Secondary symptoms, which can respond to treatment, occur in association with or result from positive symptoms, affective symptoms, medication side effects, environmental deprivation, or other treatment- or illnessrelated factors (Figure 1). ${ }^{7}$ For example, negative symptoms could be a secondary effect of primary positive symptoms in a patient who becomes socially withdrawn after experiencing delusions of persecution or paranoia; or diminished expression could be a coping strategy in a patient who is unable to process overwhelming external stimuli associated with psychotic episodes in schizophrenia.

Although several antipsychotics have demonstrated negative symptom improvement in clinical trials that were designed to study patients with acute exacerbation of schizophrenia defined by positive symptoms, treatment response should not be inferred in this context since secondary negative symptoms can improve as a consequence of improvement in other symptom domains. ${ }^{8}$ The most likely interpretation of these results is that when symptoms such as delusions improve, patients may become less socially withdrawn. Although any improvement in negative symptoms may represent an important advance for 
Table I Proposed Negative Symptom Terminology

\begin{tabular}{|c|c|}
\hline Term & Proposed Definition \\
\hline Negative symptoms & $\begin{array}{l}\text { Broadly defined as a reduction of normal functions either related to motivation and interest (eg, avolition, anhedonia, } \\
\text { and asociality) or to expressive functions (eg, blunted affect and alogia) }\end{array}$ \\
\hline Deficit syndrome & $\begin{array}{l}\text { A symptom complex characterized by primary and enduring negative symptoms that are present for most of the } \\
\text { preceding } 12 \text { months (including during periods of clinical stability); they are caused by a specific disease process that is } \\
\text { separate from the genetic and neurobiological factors that contribute to nondeficit schizophrenia }\end{array}$ \\
\hline $\begin{array}{l}\text { Predominant negative } \\
\text { symptoms }\end{array}$ & $\begin{array}{l}\text { Clinically relevant negative symptoms of greater relative severity than co-occurring positive symptoms; no duration is } \\
\text { specified so symptoms could be present for a relatively short time period or they could be long-standing }\end{array}$ \\
\hline $\begin{array}{l}\text { Prominent negative } \\
\text { symptoms }\end{array}$ & $\begin{array}{l}\text { Pronounced and clinically relevant negative symptoms of unspecified duration; reflects the clinical reality of most } \\
\text { patients whose illness does not have a clear prominence of either positive or negative symptoms, and may be } \\
\text { characterized by both }\end{array}$ \\
\hline $\begin{array}{l}\text { Primary negative } \\
\text { symptoms }\end{array}$ & Negative symptoms that are thought to be intrinsic to the underlying pathophysiology of schizophrenia \\
\hline $\begin{array}{l}\text { Secondary negative } \\
\text { symptoms }\end{array}$ & $\begin{array}{l}\text { Negative symptoms that are thought to be related to other factors, such as psychiatric or medical comorbidities, } \\
\text { treatment adverse effects, or environmental factors }\end{array}$ \\
\hline $\begin{array}{l}\text { Persistent (enduring) } \\
\text { negative symptoms }\end{array}$ & $\begin{array}{l}\text { Primary negative symptoms or secondary negative symptoms that have not responded to treatment for a minimum of } \\
6 \text { months, interfere with normal role functioning, and persist during periods of clinical stability }\end{array}$ \\
\hline
\end{tabular}

patients with schizophrenia, primary negative symptoms or negative symptoms that persist once a patient's positive symptoms are effectively managed, remain a considerable clinical challenge since they generally do not respond well to currently available antipsychotic treatment with dopamine $\mathrm{D}_{2}$ antagonists or partial $\mathrm{D}_{2}$ agonists.

While the distinction between primary and secondary negative symptoms is important for researchers and clinical trial design, these symptoms can be difficult to differentiate. As such, the clinical focus should be on managing all negative symptoms that affect patients, do not respond to the current treatment, persist during periods of clinical stability, and interfere with normal role functions. From this viewpoint, clinicians can appreciate that any patient with a clinically significant level of negative symptoms, either alone (ie, predominant negative symptoms) or concurrently with positive symptoms (ie, prominent negative symptoms), can benefit from appropriate clinical management.

\section{Negative Symptom Course}

Negative symptoms have been reported as among the most common first symptom of schizophrenia, ${ }^{9}$ although they generally do not represent the reason that clinical care is initially sought for patients. Genetic contributions, prenatal events, and poor premorbid adjustment may all contribute to the development and evolution of early negative symptoms in psychotic illnesses. ${ }^{10}$
Negative symptoms commonly appear during the prodromal phase of schizophrenia and before the first acute psychotic episode (Figure 2). ${ }^{2,9-11}$ Among patients with negative symptoms, $73 \%$ had them before the onset of positive symptoms and $20 \%$ experienced them within the same month as positive symptoms. ${ }^{11}$ Prodromal onset of negative symptoms has been characterized as a risk factor for the switch to psychosis $^{12,13}$ and it is associated with negative symptoms in the first psychotic episode. ${ }^{14}$ Negative symptoms can also present during the psychotic phase of illness, so clinicians should be mindful of positive symptoms that are accompanied by decreased emotional expression, social withdrawal, and functional deterioration. ${ }^{10}$

The long-term course of negative symptoms is unclear, with some studies reporting relative stability of symptoms over time, and others finding that negative symptoms could fluctuate or be reversible. ${ }^{16-20}$ Similarly, the distribution of negative versus positive or mixed presentations is unclear and may differ across samples.

\section{Negative Symptom Prevalence}

Evidence consistently supports the concept that negative symptoms constitute a distinct group of symptoms in schizophrenia that are separate from positive symptoms, depression and anxiety, and disorganized thought, speech, and behavior; higher prevalence of negative symptoms is noted among men, the unemployed, and in individuals 


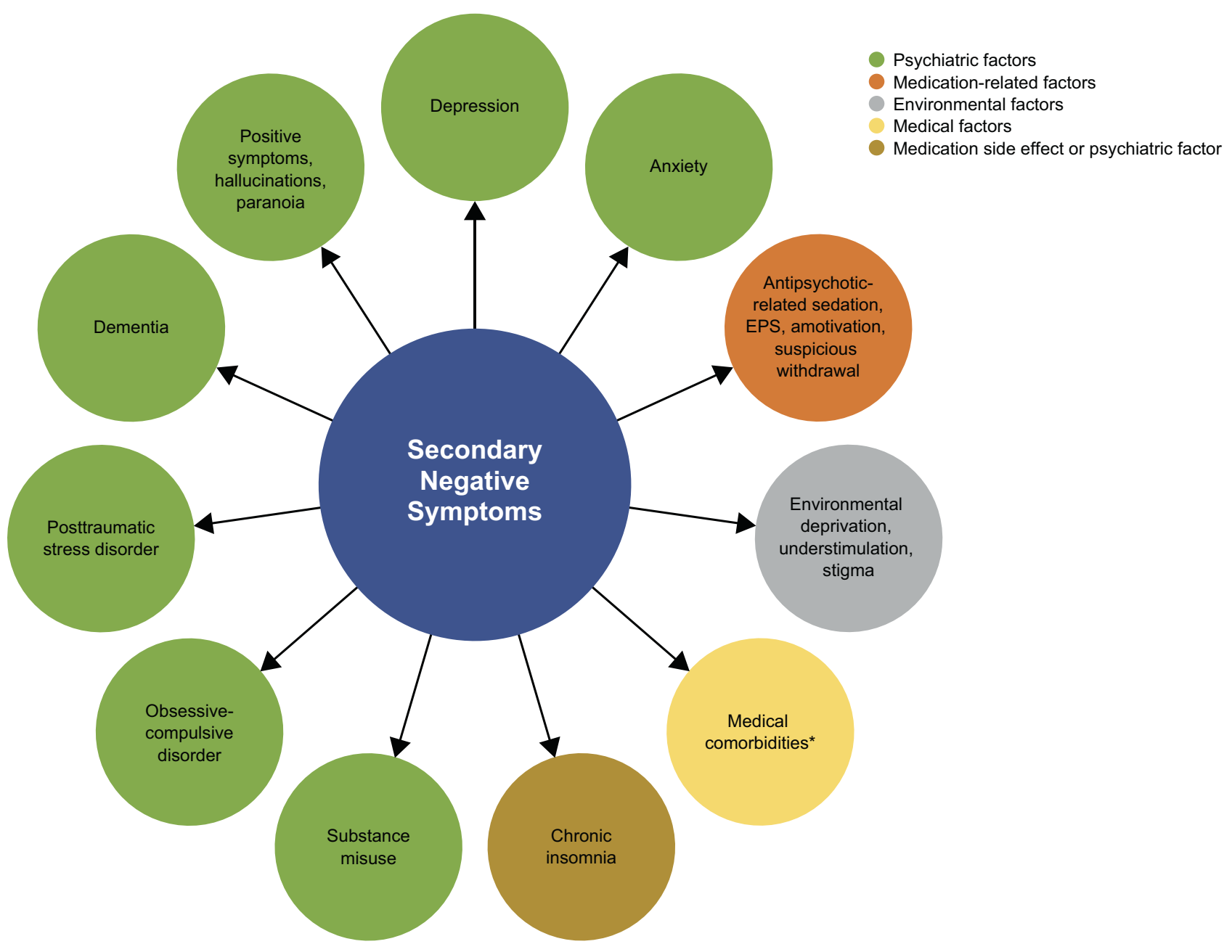

Figure I Actionable factors that cause or contribute to secondary negative symptoms.

Notes: *Including Huntington's disease, multiple sclerosis, Parkinson's disease, traumatic brain injury, chronic pain, sleep apnea, temporal lobe epilepsy.

with reduced functioning. ${ }^{3,6}$ Although negative symptom prevalence varies according to what defining terminology is used, clinicians should be mindful that up to $60 \%$ of patients with schizophrenia have prominent or predominant negative symptoms that are clinically relevant and need treatment. ${ }^{21,22}$

Negative symptoms are common and can occur at any point during the course of illness; for example, at least 1 negative symptom was noted in up to $90 \%$ of patients having a first psychotic episode, while $35-70 \%$ of patients continued to have clinically significant negative symptoms that persisted after treatment. ${ }^{11,23}$ In routine clinical practice, $61 \%$ of stable outpatients with schizophrenia who were receiving antipsychotic treatment were found to have at least 1 symptom of moderate severity or worse; 5 PANSS Negative Subscale items (blunted affect, emotional withdrawal, poor rapport, social withdrawal, verbal fluency) were included in the evaluation. ${ }^{21}$ Social withdrawal (48\%), emotional withdrawal (42\%), and poor rapport (39\%) were among the most common symptoms, and $19 \%$ of patients had all 5 negative symptoms. Likewise, in an analysis of 20 placebo-controlled studies of secondgeneration antipsychotics $(n=7450), 62 \%$ of patients met the criteria for prominent negative symptoms (score of at least moderate or moderately severe on multiple PANSS Negative symptoms) and after 6 weeks of treatment, onethird of actively treated patients still had prominent negative symptoms. ${ }^{22}$ In the same analysis, $50 \%$ of patients were characterized as having predominant negative symptoms, defined as a PANSS Negative Subscale score greater than a Positive Subscale score. Further, in the Clinical Antipsychotic Trials of Intervention Effectiveness (CATIE) study ( $\mathrm{n}=1442$ ), one of the largest individual controlled studies in schizophrenia, prominent negative 


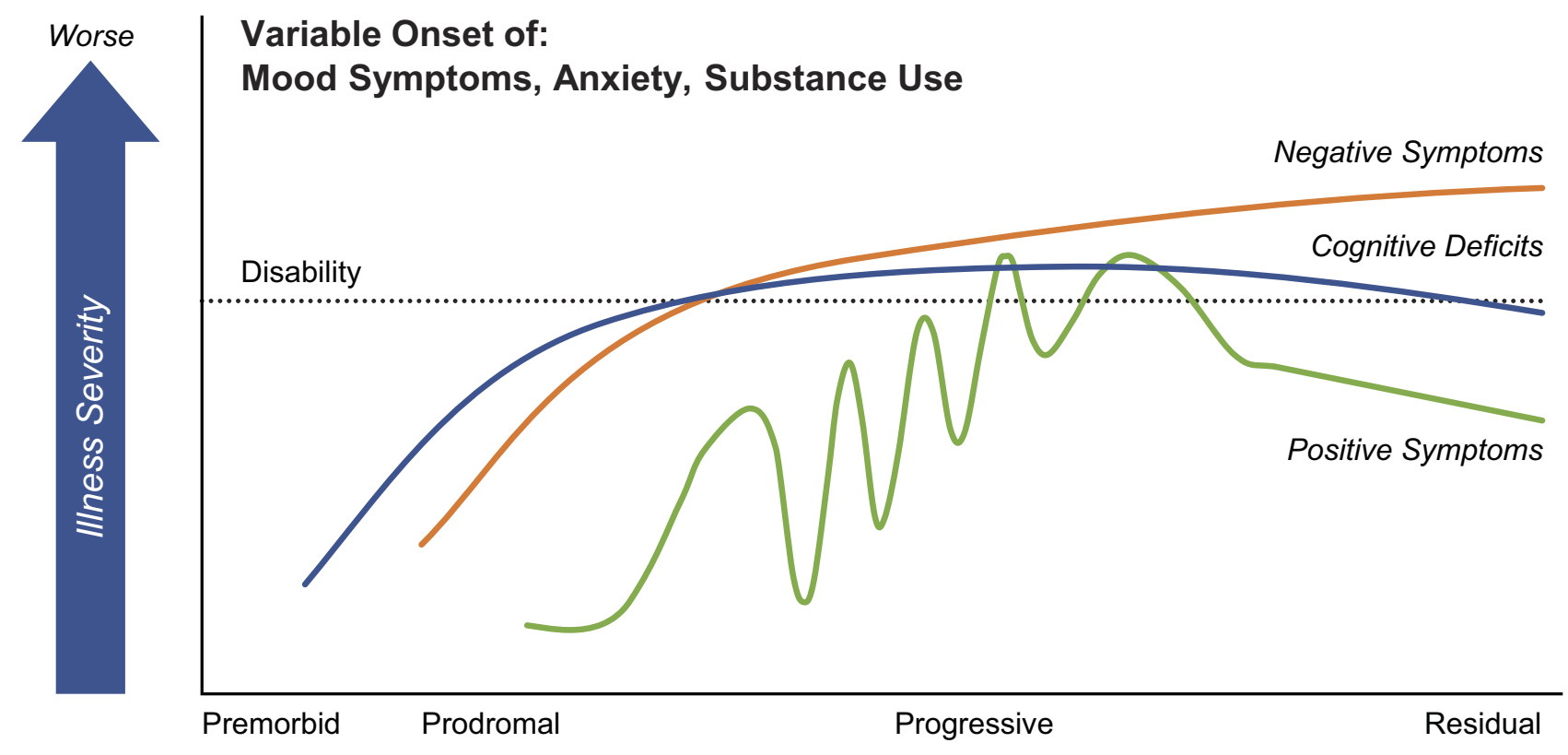

Course of Illness over Time

Figure 2 Schematic course of negative symptoms in schizophrenia. Negative symptoms are present throughout the course of schizophrenia. They can occur early, persist over time, increase in severity, and remain between acute episodes of illness. Correll, C. The Prevalence of Negative Symptoms in Schizophrenia and Their Impact on Patient Functioning and Course of Illness. The Journal of Clinical Psychiatry. 74(2):e04, 2013. Copyright 2019, Physicians Postgraduate Press. Reprinted by permission. ${ }^{15}$

symptoms were also common (40\%), with $19 \%$ of outpatients having prominent negative symptoms without prominent positive symptoms and $21 \%$ having both prominent positive and negative symptoms. ${ }^{24}$ Collectively, studies support that negative symptoms are common in schizophrenia and can occur in every phase of the illness.

\section{Burden of Negative Symptoms, and Functional and Cognitive Impairment}

Compared with positive symptoms, which can be managed in many patients with currently available dopamine $\mathrm{D}_{2}$ partial agonists and antagonists, negative symptoms have a higher burden of illness. This pronounced illness burden can be attributed to the limited number of effective and evidence-based treatment options, although underrecognition of these symptoms also plays a role. It is very important to assess and address negative symptoms in an effort to lessen the associated burden on patients, caregivers, and healthcare systems. ${ }^{2}$

Negative symptom severity in schizophrenia has been consistently linked to worse functional outcomes in areas such as impaired occupational and academic performance, household integration, social functioning, participation in activities, and quality of life. ${ }^{25}$ Avolition has been proposed as a key negative symptom construct related to functional deterioration. ${ }^{5}$ Loss of motivation is thought to be associated with clinical features that are observable as changes in both individual (ie, apathy, blunted affect) and social (ie, asociality and alogia) behaviors. Although affective symptoms may appear to be anhedonic in nature, individuals with schizophrenia seem to be able to experience consummatory pleasure, with functional decline specifically related to the inability to anticipate pleasure in pursuing or achieving goal-directed behavior. ${ }^{25}$ Deficits in anticipatory pleasure and reduced pleasure-seeking behavior may be related to reward processing disturbances (eg, deficits in reward learning, reward prediction, accurate and adaptive internal value representations), with subsequent impairment resulting from the inability to use reward-associated information to guide future motivated behavior. ${ }^{25}$

Negative symptoms and neurocognitive dysfunction affect around $40 \%$ and $80 \%$ of individuals with schizophrenia, respectively. ${ }^{6}$ Although negative and cognitive symptoms are considered separate domains of psychopathology in schizophrenia, shared features suggest that symptoms from one domain may reinforce the other or that they may 
originate in similar neurobiological structures. ${ }^{25,26}$ For example, impairment of executive function may contribute to avolition by interfering with the goal-directed behavior that is necessary to acquire reward. ${ }^{27}$ Similarly, impairment in the ability to retrieve information from memory may underpin alogia and poor social cognition, being caused by or resulting in asociality. ${ }^{27}$ Negative symptoms and cognitive deficits are closely associated with real-world functioning in schizophrenia, although adequate functioning is a complex phenomenon and several factors contribute. ${ }^{28,29}$ Interventions for cognitive and negative symptoms partly overlap, with a combination of psychopharmacological and psychosocial interventions needed to adequately treat secondary negative symptoms that may be contributing to impairment and to address patient's individual cognitive needs. ${ }^{6}$

\section{The Neurobiology of Negative Symptoms}

Negative symptoms of schizophrenia are likely to be the result of irregularities of distributed neural networks (eg, frontocortico-temporal, cortico-striatal), as opposed to the disruption of any discrete region of the brain. ${ }^{26}$ Although several hypotheses may be implicated in the pathophysiology of schizophrenia and negative symptoms, the dopamine and glutamate hypotheses are among those that are best supported by current evidence. The dopaminergic hypothesis of schizophrenia proposes that positive symptoms are the result of hyperactivity of dopaminergic neurotransmission in limbic pathways, while negative symptoms, loss of motivation, and impairment in cognition are thought to arise from hypodopaminergic functioning in the frontal lobe and additional mesolimbic structures. ${ }^{30,31}$ However, recent imaging studies suggest that abnormal dopamine function in schizophrenia may be in the dorsal rather than in the limbic striatum. ${ }^{32}$

Due to their localization in mesolimbic regions of the brain that control reward, emotion, and motivation, dopamine $\mathrm{D}_{3}$ receptors may also play a role in the modulation of negative symptoms, mood, and cognition. ${ }^{33-37}$ This hypothesis has been supported by findings from animal models, which have suggested that antagonism and partial agonism at dopamine $\mathrm{D}_{3}$ receptors can mediate improvements in social interaction, novel object recognition, as well as displaying $\mathrm{D}_{3}$-receptor mediated anti-anhedonic and procognitive effects in rodents. ${ }^{38-40}$ The mechanism by which these effects may occur is not clear, although it is possible that antagonism of $\mathrm{D}_{3}$ receptors in the midbrain (eg, ventral tegmental area) could enhance dopamine neurotransmission to the prefrontal cortex $^{41,42}$ and the nucleus accumbens, ${ }^{43-45}$ two areas of the brain where hypodopaminergic functioning has been linked to negative symptoms and mood deficits. ${ }^{46,47}$ This normalization of dopamine release in the prefrontal cortex could result in increased activation of $D_{1}$ receptors, which in turn could mediate improvements in cognition and negative symptoms. ${ }^{47}$ $\mathrm{D}_{3}$ receptors have also been associated with increased acetylcholine release in the prefrontal cortex,${ }^{41}$ regulation of glutamatergic excitability in the prefrontal cortex, ${ }^{48,49}$ and regulation of dopamine, CREB phosphorylation, ${ }^{50}$ and gamma oscillations ${ }^{51}$ in the hippocampus, all mechanisms that could potentially contribute to the modulation of cognition and/or mood symptoms associated with schizophrenia. As such, $\mathrm{D}_{3}$ antagonists and partial agonists may provide benefits in negative or cognitive symptoms.

Alternatives to the dopamine hypothesis suggest that other neurotransmitters, particularly glutamate, contribute to the development of symptoms in schizophrenia. The glutamate hypothesis is based on the clinical observation that chronic blockade of glutamate neurotransmission by antagonists at the N-methyl-D-aspartate (NMDA) receptor subtype (eg, ketamine, phencyclidine) produces a pathophysiological state resembling schizophrenia, including both positive and negative symptoms (whereas the dopamine model of amphetamine-induced psychosis only produces positive symptoms). ${ }^{52,53}$ Although several studies have found that drugs facilitating glutamate neurotransmission by acting at the glycine accessory site of the NMDA receptor (eg, D-cycloserine) improve symptoms of schizophrenia and enhance the efficacy of antipsychotic drugs, notably against the negative symptoms of the disease, ${ }^{54-56}$ evidence is equivocal. ${ }^{57}$ Positive findings have led to the supposition that schizophrenia may result from glutamate deficiency, with suspected abnormalities in NMDA receptor function contributing to antipsychotic-resistant symptoms,${ }^{58}$ but additional studies are needed. Additional mechanisms of action, including metabotropic glutamatergic receptor (mGluR2) agonism, alpha-7 nicotinic receptor agonism, and central nervous system stimulant activity, are also targets for drug development in negative symptoms of schizophrenia. ${ }^{59}$

Of note, however, the dopamine and glutamate hypotheses of schizophrenia are not mutually exclusive, with evidence in the literature supporting a role for both in the neurobiology of schizophrenia. Indirect clinical evidence suggests an important interaction between dopamine receptors and NMDA receptors in critical brain regions, such as the hippocampus, and between glutamatergic afferents and subcortical dopaminergic nuclei. ${ }^{52}$ Additionally, a link between cortical glutamate/NMDA deficiency and subcortical dopamine hyperactivity, particularly in 
the mesolimbic pathway, has been hypothesized in schizophrenia, with some evidence that hyperactivity produced by NMDA receptor blockade is dependent upon stimulation of the dopamine $\mathrm{D}_{3}$ receptor subtype. ${ }^{60}$ In any case, a better understanding of the neurobiology of negative symptoms constitutes an important step toward the identification of treatment targets and the development of novel interventions for negative symptoms that may improve treatment efficacy and outcomes overall.

\section{Clinical Presentation, Diagnosis, and Identification of Negative Symptoms}

It is generally accepted that negative symptoms include 5 key constructs, ${ }^{61}$ which can be further categorized into 2 independent factors (Figure 3). ${ }^{2,62,63}$

Although the presence of negative symptoms is not mandatory for a diagnosis of schizophrenia, negative symptoms (ie, diminished emotional expression and avolition), are 1 of the 5 symptom criteria taken into consideration in the Diagnostic and Statistical Manual of Mental Disorders (DSM-5). ${ }^{64}$ Diminished expression, which includes reduction in the expression of facial emotions, eye contact, and speech intonation, and reduction in head, hands, and face movement that gives emotional emphasis to speech, is generally observable during a clinical interview. Avolition, indicating decrease in self-motivated and self-initiated purposeful activities, requires inquiry into patient's behaviors outside the interview setting. A level of functioning in work, school, relationships, or selfcare that is markedly below the level that has previously been achieved is also diagnostic and suggests the presence of avolition and the reduced drive to pursue goal-directed behavior.

Clinical recognition of negative symptoms is challenging because patients with schizophrenia may not be aware of the impact of negative symptoms and they rarely present with negative symptom complaints. ${ }^{6}$ If patients lack insight into their symptoms and corroborating information from people in the patient's life is lacking, additional responsibility is placed on clinicians to recognize negative symptoms, which is particularly important because high negative symptom burden predicts poor treatment response and functional outcomes. ${ }^{6}$ Positive symptoms (eg, delusions, hallucinations) and signs of relapse, hostility, or suicidality often take clinical precedence over the less obvious and emergent negative symptoms, further complicating the identification of negative symptoms during a short clinical visit. Furthermore, while clinicians have been well trained to assess and treat positive symptoms of schizophrenia, many are unsure of the best way to identify and treat negative symptoms. ${ }^{2}$

\section{Negative \\ Symptoms}

Factors

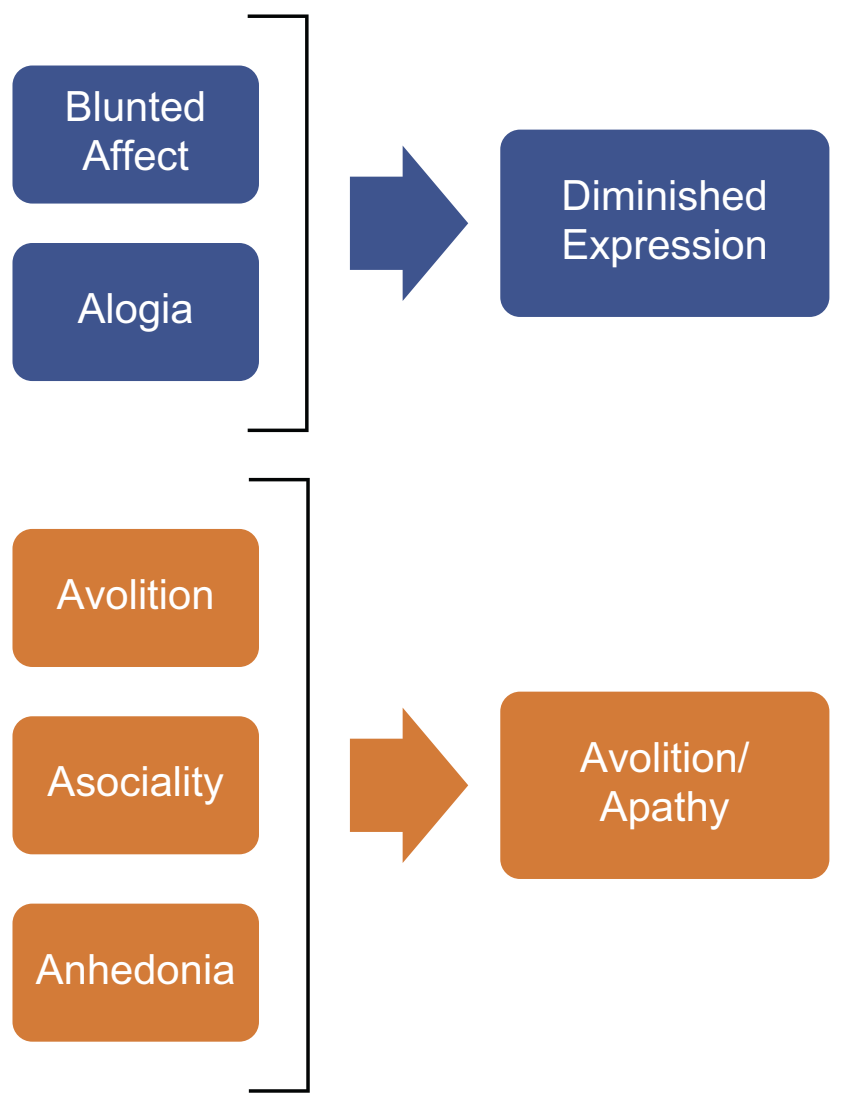

Figure 3 Key negative symptom constructs. Blunted affect=decreased expression of emotion; alogia=reduction in quantity of words spoken; avolition=reduced initiation and persistence of goal-directed activity due to decreased motivation; asociality=reduced social interactions and initiative due to decreased interest in relationships with others; anhedonia=reduced experience of pleasure during an activity or in anticipation of an activity.

When seeing a patient with schizophrenia, clinicians should be on the lookout for a general presentation that suggests the presence of negative symptoms, including signs such as communication difficulties, flat affect, limited emotion, social inactivity, low motivation, and retarded psychomotor activity (Figure 4). While some of these problems are observable during clinical assessment, others need to be elicited through questions and discussions with the patient, family members, and caregivers, making informant input critical to the accurate assessment of the presence, severity, and impact of negative symptoms.

\section{Negative Symptom Assessment Rating Scale Assessments}

Several validated and well-established assessment tools, such as the Positive and Negative Syndrome Scale 


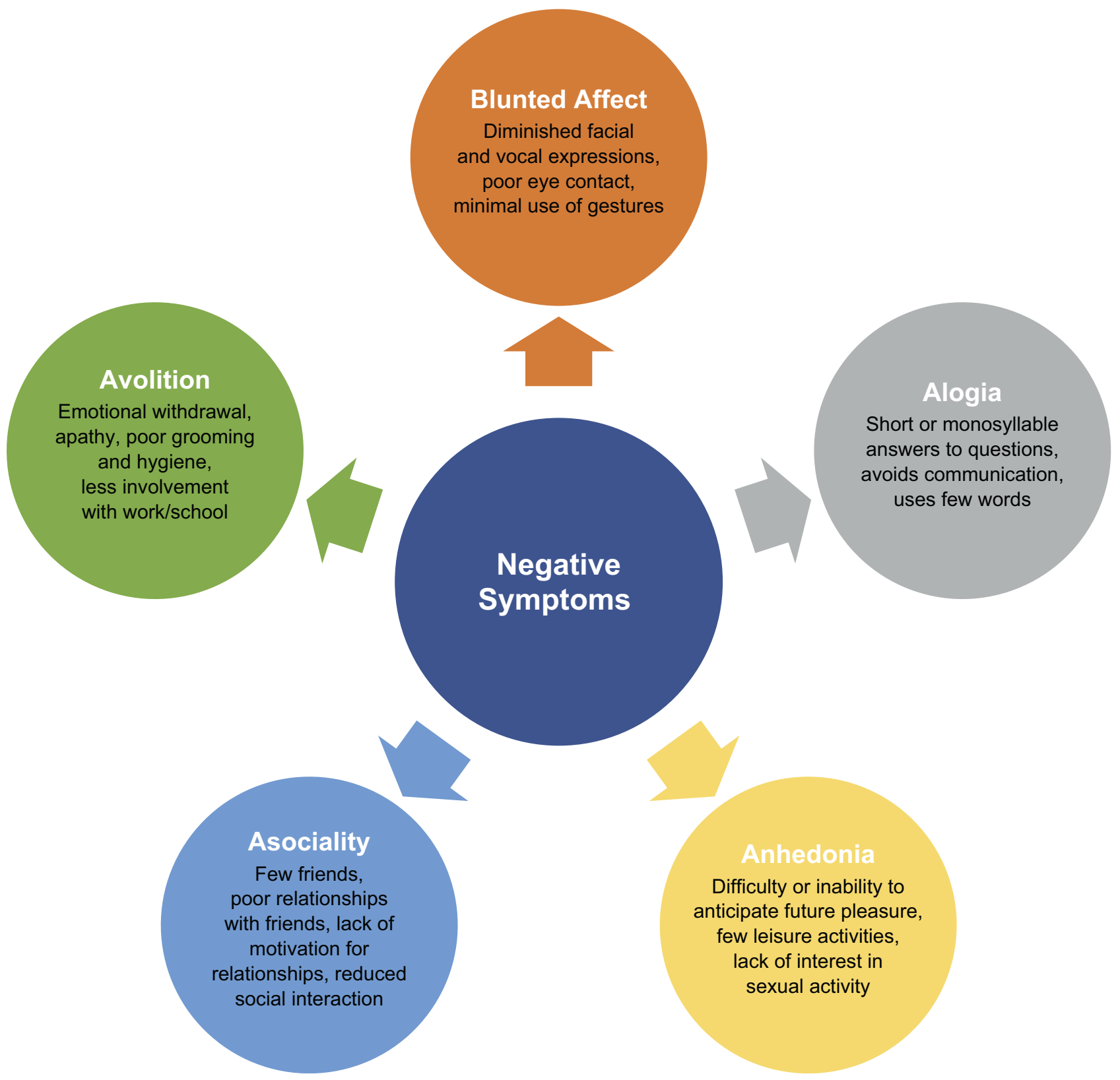

Figure 4 Clinical presentation of negative symptoms.

(PANSS), ${ }^{65}$ the Scale for the Assessment of Negative Symptoms (SANS), ${ }^{66}$ and the 16-item Negative Symptom Assessment (NSA-16) ${ }^{67}$ are available to evaluate negative symptoms and track their course over time. Of note, these scales only measure negative symptoms at a single timepoint and may be limited by the inclusion of items that are no longer considered relevant to the negative symptom domain (eg, difficulties in abstract and stereotyped thinking, inattentiveness). Newer scales that have been developed include the Clinical Assessment Interview for Negative Symptoms (CAINS), ${ }^{68}$ which covers all 5 negative symptom domains, and the Brief Negative Symptom Scale (BNSS). ${ }^{69}$ The BNSS includes the 5 negative symptom constructs and was developed with clinical setting use in mind; 13 items are categorized into 6 subscales and ratings are based on a short interview of $\sim 20$ mins. None of these scales consider whether symptoms are primary or secondary to another aspect of illness, and administration may be limited by time constraints and the availability of trained raters. ${ }^{10,70}$

Given the challenges associated with negative symptoms in the clinic, an easy-to-use instrument for rapid screening and assessment can benefit clinicians, patients, and families alike. One such tool is the NSA- $4,{ }^{71}$ a condensed version of the NSA-16 that rates behavior, 
not psychopathology; due to its focus and brevity, it is much more scalable and usable in busy clinical contexts. The NSA-4 consists of 4 verbatim items from the full rating scale (restricted speech quantity, reduced emotion, reduced social drive, and reduced interests) and a global rating of the overall impression of negative symptom severity. Each item compares the patient's behavior with that of a healthy person and anchor points are provided to help clinicians rate the severity of each symptom. In a study of over 400 mental health professionals, all NSA-4 items were rated by participants within 1 rating point of an expert consensus rating $82-91 \%$ of the time, regardless of geographical region, professional credential, or familiarity with the use of schizophrenia rating scales. ${ }^{71}$ This study and others ${ }^{72}$ suggest that measurement-based assessment can be used successfully in clinical practice by trained direct-care staff, potentially improving symptom recognition and evaluation of treatment response in daily practice.

\section{Assessment Beyond the Rating Scale}

Timely and successful assessment and management of negative symptoms are critical aspects of good patient care. Since some patients may have limited selfawareness of negative symptoms as a part of their illness, clinicians must rely on observations during the interview, input received from informants, and information collected through revealing questions. Careful assessment of patient responses to questions can help determine if a diagnosis other than negative symptoms is applicable or may rule out other conditions (eg, comorbid depression) that are common in people with schizophrenia-spectrum disorders. Answers to questions such as "What kind of mood are you in?" or "How do you feel today?" can help a clinician judge a patient's affect and may provide important correlates to vocal tone, gestures, and facial expressions when evaluating the emotional expression. Questions should be phrased to elicit broad responses in order to demonstrate whether a patient is able to elaborate on a response without prompting, participates in enjoyable activities to assess for anhedonia, has social contacts to assess social drive, and is goal oriented and productive. Additional examples of questions that can elicit informative responses include: How do you spend a typical day? What do you do for fun? Have you had a chance to meet up with people outside of your family recently? and Would you like to have a job? Follow-up responses such as "Tell me about that" or "What would be a good first step to get a job?" should encourage further communication from the patient.
For patients with more severe negative symptoms, some fundamental signs can be identified solely by observation of behaviors, such as poor grooming and hygiene, and reduced or impoverished content of speech. In the future, data collected through digital technology, such as smartphone applications, are expected to become increasingly available and used to enhance various aspects of patient assessment and care in the management of schizophrenia generally and negative symptoms in particular. $^{73}$ Technologies to track symptoms in outpatients, prevent relapse, encourage medication adherence, offer real-time support, encourage physical activity, and increase access to services may help clinicians better assess and manage negative symptoms and patient status.

Although negative symptoms are classically described in relationship to schizophrenia, they also occur in other illnesses. ${ }^{10}$ It is important for clinicians to rule out differential medical (eg, multiple sclerosis, Parkinson's disease) or psychiatric (eg, depression, anxiety, obsessivecompulsive disorder, posttraumatic stress disorder, autism, intellectual disability, substance misuse) conditions that may have negative symptom-like presentations so that appropriate treatment can be offered (see Figure 1).

While being aware that negative symptoms can be intrinsic to schizophrenia or related to an underlying cause is important, differentiating between them can be difficult, if not impossible. As such, clinicians should be vigilant for all clinically relevant negative symptoms in order to manage them properly and improve patient outcomes. Given that a majority of patients with schizophrenia may have prominent negative symptoms, ${ }^{21,22}$ a personalized medicine approach, in which treatment is tailored to the patient's individual symptom profile, is advocated. Clinicians can provide the most appropriate treatment for each patient by observing their behavior, questioning them and their family members or friends, administering a formal assessment such as the NSA-4, considering differential medical diagnoses, and addressing factors that are associated with secondary negative symptoms.

\section{Treatment \\ Pharmacologic Treatment}

Antipsychotic medication is the cornerstone of treatment for acute psychotic episodes, improving symptoms of schizophrenia in $81 \%$ of patients with first episode schizophrenia on average and improving symptoms of chronic schizophrenia in $51 \%$ of patients. ${ }^{74}$ Further, after an acute episode has resolved, antipsychotic medications 
reduced the risk of psychotic relapses at 7-12 months (drug $=27 \%$, placebo $=64 \%$ ). ${ }^{75}$ However, most currently available drugs have limited effects on negative symptoms of schizophrenia that are not secondary to positive symptoms ${ }^{76-78}$ and to date no agent is approved by the FDA for the treatment of negative symptoms.

Few studies have been prospectively designed to assess the effect of treatment on persistent negative symptoms, with most reports of improvement in negative symptoms being based on short-term studies in patients with acute psychotic illness and concurrent negative symptoms. ${ }^{8,79}$ As such, it is difficult to determine if negative symptom improvement in most reported studies is a genuine effect of treatment or secondary to improvements in other symptom domains (ie, positive, depressive, extrapyramidal), and long-term evidence is lacking. ${ }^{78,80,81}$ In a metaanalysis of randomized, controlled, blinded, antipsychotic drug trials in patients with schizophrenia and either predominant or prominent negative symptoms, low-dose amisulpride, which is approved for negative symptoms in a limited number of European countries, was the only antipsychotic that was superior to placebo in the treatment of predominant negative symptoms; however, a parallel reduction of depression was also observed making it difficult to assess whether the reduction in negative symptoms was a function of improvement in depression. ${ }^{82}$

To date, the only prospective, large-scale, randomized, double-blind evidence demonstrating the superiority of one approved antipsychotic over another in the treatment of negative symptoms comes from a rigorously designed 26week study comparing the effects of fixed-dose cariprazine ( $3 \mathrm{mg} / \mathrm{d}, 4.5 \mathrm{mg} / \mathrm{d}$ [target dose], or $6 \mathrm{mg} / \mathrm{d}$ ) and risperidone ( $3 \mathrm{mg} / \mathrm{d}, 4 \mathrm{mg} / \mathrm{d}$ [target dose], or $6 \mathrm{mg} / \mathrm{d}$ ) on predominant negative symptoms in patients with stable and limited positive symptoms, and without relevant depression or extrapyramidal symptoms. ${ }^{83}$ This study was conducted to test the hypothesis that cariprazine, as a dopamine $\mathrm{D}_{3}$-preferring $\mathrm{D}_{3}$ $/ \mathrm{D}_{2}$ receptor partial agonist and serotonin $5-\mathrm{HT}_{1 \mathrm{~A}}$ receptor partial agonist, may be more beneficial than a $\mathrm{D}_{2}$-preferring antagonist for treating negative symptoms and cognition in patients with schizophrenia. ${ }^{34,84}$ In this 26 -week study, significant differences and clinically relevant improvement in both negative symptoms and functional impairment were demonstrated in favor of cariprazine over risperidone, suggesting a clinically meaningful treatment benefit for cariprazine in negative symptoms. Of note, changes in symptoms from other domains were small and similar for cariprazine and risperidone, indicating that improvement was specific to negative symptoms and not related to changes in positive symptoms, EPS, or depressive symptoms; rates of EPSrelated TEAEs were also similar for cariprazine (14\%) and risperidone (13\%). Moreover, superiority in regard to negative symptom improvement was also accompanied by significant advantages for cariprazine over risperidone on the Clinical Global Impressions-Improvement Scale ${ }^{85}$ and the Personal and Social Performance Scale, ${ }^{86}$ indicating that the improvement of the negative symptoms with cariprazine additionally led to clinically meaningful advantages.

Beyond antipsychotic monotherapy, other drugs have also been used adjunctively with antipsychotics for the treatment of negative symptoms. Several trials have shown modest efficacy for adjunctive antidepressants, and limited evidence against negative symptoms exists for other adjunctive agents including glutamatergic compounds (eg, glycine, D-serine, D-cycloserine), minocycline, dopamine agonists (eg, selegiline, modafinil), and cholinergics (eg, galantamine, donepezil). . $^{8,78,87-90}$ However, evidence for adjunctive efficacy is limited by methodological issues in several studies, suggesting that higher-quality trials and patient-based meta-analyses are needed to determine whether some patients might benefit from combination treatment. ${ }^{88}$ Additionally, some research has been done on repurposed drugs (ie, minocycline, estrogen, raloxifene, folate), but support for treatment trials in drugs that are already approved for other uses, or are generic or over-the-counter, is limited by lack of financial incentive. ${ }^{91}$ For now, no single cotreatment strategy has sufficient evidence to be recommended for the treatment of patients with schizophrenia. ${ }^{88}$

Given the considerable unmet medical need associated with negative symptoms, drug development is active in this therapeutic area for agents with activity at different receptors including NMDA receptors, alpha 7 nicotinic receptors, ${ }^{87}$ and $5-\mathrm{HT}_{2 \mathrm{~A}}$ and sigma-2 receptors. ${ }^{92}$ Of note, roluperidone (MIN-101), an antagonist at both sigma-2 and $5-\mathrm{HT}_{2 \mathrm{~A}}$ receptors and without direct dopamine affinities, has demonstrated statistically significant efficacy in reducing negative symptoms versus placebo in stable patients with schizophrenia in a phase $2 \mathrm{~b}$ trial. ${ }^{92}$ Since MIN-101 is being developed in monotherapy exclusively for the treatment of negative symptoms, it has only been studied in patients whose positive symptoms were stable. Moreover, it is still unclear how many patients with schizophrenia will remain stable on MIN-101 while being off directly dopamine modulating medications and whether ongoing Phase 3 trials will replicate its negative symptom advantage, which 
was partly due to a rarely observed absence of negative symptom improvement on placebo. Further, meta-analyses have shown that antidepressants may potentially be beneficial in treating negative symptoms. ${ }^{89,90}$ Notably, in these analyses, effect sizes were generally small and it is unclear if improvement in undeclared or unrecognized depression may have been responsible for some of the negative symptom improvement. Moreover, the quality of some of the meta-analyzed studies may have been problematic, which further confounds the overall outcomes.

Additionally, some medical devices, using approaches such as deep transcranial magnetic stimulation and transcranial direct current stimulation, are also under investigation for the treatment of negative symptoms. ${ }^{87,93}$ While treatments that are eventually determined to be effective all begin with small proof-of-concept studies, early success does not guarantee efficacy in later stages of development and the efficacy of new drug candidates for the treatment of negative symptoms is still uncertain. ${ }^{94}$

\section{Psychosocial Treatment}

Given the limited effective pharmacologic interventions to treat patients with negative symptoms of schizophrenia, it is important that clinicians are aware of psychosocial interventions that can be used in conjunction with antipsychotics. Several psychological variables, including defeatist beliefs, negative expectations, and asocial preferences, are associated with negative symptoms. ${ }^{95}$ Therefore, interventions aimed at addressing attitudes, behaviors, and poor psychosocial functioning may help patients gain insight into how their symptoms affect their outlook. General behavioral interventions, including a focus on healthy lifestyles, with emphasis on exercise, sleep, diet, smoking cessation, appropriate alcohol consumption, and social participation, should always be suggested in the course of treatment. ${ }^{96}$ While skill-based interventions, such as social skills training ${ }^{76,97}$ and cognitive remediation therapy ${ }^{98,99}$ have some evidence for negative symptom improvement, the most widely studied psychological intervention is cognitive behavioral therapy (CBT). CBT supports awareness of the link between a patient's thoughts, behaviors, and feelings in an effort to change symptoms and functioning. ${ }^{76}$ As an adjunct to antipsychotic treatment, CBT has demonstrated positive, but moderate, effects on negative symptoms, with a reduction of apathy and improved motivation. ${ }^{98,100,101}$

Family interventions provide support to help patients and family members cope with the burden of negative symptoms through psychoeducation, communication training, behavioral problem solving, and crisis management. ${ }^{76}$ Motivation and Enhancement Training (MOVE), a novel treatment that combines environmental support, CBT, skills training, and other psychosocial modalities, has also been assessed as a specific negative symptom intervention, with preliminary results suggesting some improvement, but only after 9 months of therapy. ${ }^{102,103}$ Despite mixed and inconsistent results, referring patients to psychosocial treatment may be an important way for clinicians to support patients and their families as they cope with negative symptoms and attempt to improve outcomes and quality of life. Although additional clinical trials are needed to improve the evidence base for psychosocial interventions in negative symptoms of schizophrenia, positive outcomes in some trials suggest a benefit for some patients and even small changes could be clinically relevant for patients with negative symptoms who have limited treatment options.

\section{Best Practices for Managing Negative Symptoms in the Clinic}

Negative symptoms are common in schizophrenia and over half of patients will experience clinically relevant negative symptoms that need treatment at some point. $^{21,22}$ In addition to the limited efficacy of most available pharmacological treatments, negative symptom characteristics are a challenge in the clinic since some patients may lack insight into the extent and impact of their symptoms. Patients rarely present with negative symptom complaints and more immediately pressing positive symptoms may distract clinicians from the negative symptom burden. Given the difficulty in differentiating negative symptoms that are intrinsic to schizophrenia from negative symptoms resulting from another underlying cause, clinicians should carefully monitor and actively manage all clinically relevant negative symptoms (Table 2).

\section{Conclusion}

Clinically relevant negative symptoms of schizophrenia, which occur in a majority of patients, need to be recognized, assessed, and as well managed as possible in order to achieve improved outcomes for patients. Because negative symptoms are often not recognized by clinicians and limited evidence-based treatment is available, negative symptoms are more closely related to poor patient functioning, worse quality of life, and lowered productivity 
Table 2 Tips for Managing Negative Symptoms in the Clinic

\begin{tabular}{|c|c|}
\hline $\begin{array}{l}\text { Opportunities for } \\
\text { Intervention }\end{array}$ & Actions to Take \\
\hline Recognition & $\begin{array}{l}\text { After urgent symptoms are addressed, take time to focus exclusively on negative symptoms and signs } \\
\text { Pay particular attention to the patient's level of interaction, interest, and engagement } \\
\text { Evaluate body language, facial expressions, gestures, and eye contact } \\
\text { Ask questions about the patient's daily activities and interactions, social activities inside and outside the family, work } \\
\text { or school involvement, and pleasurable activities or hobbies } \\
\text { Ask informants about the patient's normal daily behavior relevant to negative symptoms } \\
\text { Consider administering the NSA-4 or another negative symptom assessment tool }\end{array}$ \\
\hline Assessment & $\begin{array}{l}\text { Assess affect and behavior that may suggest negative symptoms } \\
\text { Assess psychiatric and medical comorbidities that may present as negative symptoms or aggravate negative symptom } \\
\text { complaints } \\
\text { Assess medication side effects that may present as negative symptoms or aggravate negative symptom complaints } \\
\text { Gauge the level of impairment by comparing the patient to what would be expected from a healthy age- and sex- } \\
\text { matched individual }\end{array}$ \\
\hline Management & $\begin{array}{l}\text { Optimize current medications to treat/maintain stability of psychotic (positive) symptoms } \\
\text { Minimize medication side effects that may aggravate negative symptoms } \\
\text { Consider medication adjustment or switch to medication with efficacy in treating negative symptoms } \\
\text { Treat comorbid medical and psychiatric conditions if possible } \\
\text { Refer to a specialist for treatment of a comorbid medical condition if necessary } \\
\text { Refer to a psychologist for psychosocial intervention } \\
\text { Encourage self-care, social interaction, and environmental stimulation }\end{array}$ \\
\hline
\end{tabular}

Abbreviation: NSA-4, 4-item Negative Symptom Assessment.

than are positive symptoms, which can be better addressed by available treatment options. Targeting negative symptoms for drug development has yielded positive outcomes for select monotherapy agents in a limited number of recent well-designed clinical trials, but to date, effective treatment of negative symptoms remains an unmet medical need in schizophrenia.

\section{Acknowledgments}

Writing and editorial assistance were provided by Carol Brown, MS, of Prescott Medical Communications Group (Chicago, IL), a contractor of Allergan.

\section{Author Contributions}

C. U. Correll, and N. R. Schooler participated in the writing, editing and approval of this final version. All authors met ICMJE authorship criteria. Neither honoraria nor payments were received for authorship. All authors made substantial contributions to conception and design, acquisition of data, or analysis and interpretation of data; took part in drafting the article or revising it critically for important intellectual content; gave final approval of the version to be published; and agree to be accountable for all aspects of the work.

\section{Funding}

Allergan provided funding for medical writing assistance by Prescott Medical Communications. The Authors had full control of the preparation, review, and final approval of the manuscript, as well as the decision to submit the manuscript for publication.

\section{Disclosure}

Dr. Correll has been a consultant and/or advisor to or has received honoraria from: Alkermes, Allergan, Angelini, Boehringer-Ingelheim, Gedeon Richter, Gerson Lehrman Group, Indivior, IntraCellular Therapies, Janssen/J\&J, LB Pharma, Lundbeck, MedAvante-ProPhase, Medscape, Merck, Neurocrine, Noven, Otsuka, Pfizer, Recordati, Rovi, Servier, Sumitomo Dainippon, Sunovion, Supernus, Takeda, and Teva. He has provided expert testimony for Bristol-Myers Squibb, Janssen, and Otsuka. He served on a Data Safety Monitoring Board for Boehringer-Ingelheim, Lundbeck, Rovi, Supernus, and Teva. He received royalties from UpToDate and grant support from Janssen and Takeda. He is also a shareholder of LB Pharma. Dr. Schooler has been a consultant and/or advisor to Alkermes, Allergan, GW Pharmaceuticals, IntraCellular Therapies, Lundbeck, Roche and Sunovion. She reports personal fees from Alkermes, Allergan, GW Pharmaceuticals, 
Intracellular Therapies, Lundbeck, Roche, Sunovion, and grants from Otsuka, outside the submitted work. The authors report no other conflicts of interest in this work.

\section{References}

1. Kahn RS, Sommer IE, Murray RM, et al. Schizophrenia. Nat Rev Dis Primers. 2015;1:15067. doi:10.1038/nrdp.2015.67

2. Galderisi S, Mucci A, Buchanan RW, Arango C. Negative symptoms of schizophrenia: new developments and unanswered research questions. Lancet Psychiatry. 2018;5:664-677. doi:10.1016/S22150366(18)30050-6

3. Kirkpatrick B, Buchanan RW, Ross DE, Carpenter WT Jr. A separate disease within the syndrome of schizophrenia. Arch Gen Psychiatry. 2001;58(2):165-171. doi:10.1001/archpsyc.58.2.165

4. Milev P, Ho BC, Arndt S, Andreasen NC. Predictive values of neurocognition and negative symptoms on functional outcome in schizophrenia: a longitudinal first-episode study with 7-year follow-up. $\mathrm{Am}$ J Psychiatry. 2005;162(3):495-506. doi:10.1176/appi.ajp.162.3.495

5. Foussias G, Remington G. Negative symptoms in schizophrenia: avolition and Occam's razor. Schizophr Bull. 2010;36(2):359-369. doi:10.1093/schbul/sbn094

6. Carbon M, Correll CU. Thinking and acting beyond the positive: the role of the cognitive and negative symptoms in schizophrenia. CNS Spectr. 2014;19 Suppl 1:38-52;quiz 35-37, 53. doi:10.1017/ S1092852914000601

7. Buchanan RW. Persistent negative symptoms in schizophrenia: an overview. Schizophr Bull. 2007;33(4):1013-1022. doi:10.1093/schbul/ sbl057

8. Moller HJ, Czobor P. Pharmacological treatment of negative symptoms in schizophrenia. Eur Arch Psychiatry Clin Neurosci. 2015;265(7):567-578. doi:10.1007/s00406-015-0596-y

9. an der Heiden W, Hafner H. The epidemiology of onset and course of schizophrenia. Eur Arch Psychiatry Clin Neurosci. 2000;250 (6):292-303. doi:10.1007/s004060070004

10. Lyne J, O’Donoghue B, Roche E, Renwick L, Cannon M, Clarke M. Negative symptoms of psychosis: a life course approach and implications for prevention and treatment. Early Interv Psychiatry. 2018;12(4):561-571. doi:10.1111/eip.2018.12.issue-4

11. an der Heiden W, Leber A, Hafner H. Negative symptoms and their association with depressive symptoms in the long-term course of schizophrenia. Eur Arch Psychiatry Clin Neurosci. 2016;266 (5):387-396. doi:10.1007/s00406-016-0697-2

12. Piskulic D, Addington J, Cadenhead KS, et al. Negative symptoms in individuals at clinical high risk of psychosis. Psychiatry Res. 2012;196(2-3):220-224. doi:10.1016/j.psychres.2012.02.018

13. Velthorst E, Nieman DH, Becker HE, et al. Baseline differences in clinical symptomatology between ultra high risk subjects with and without a transition to psychosis. Schizophr Res. 2009;109(13):60-65. doi:10.1016/j.schres.2009.02.002

14. Lyne J, Renwick L, Madigan K, et al. Do psychosis prodrome onset negative symptoms predict first presentation negative symptoms? Eur Psychiatry. 2014;29(3):153-159. doi:10.1016/j.eurpsy.2013.02. 003

15. Correll C. The prevalence of negative symptoms in schizophrenia and their impact on patient functioning and course of illness. J Clin Psychiatry. 2013;74(2): $\mathrm{e} 04$.

16. Austin SF, Mors O, Budtz-Jorgensen E, et al. Long-term trajectories of positive and negative symptoms in first episode psychosis: a 10year follow-up study in the OPUS cohort. Schizophr Res. 2015;168(1-2):84-91. doi:10.1016/j.schres.2015.07.021

17. Kulhara $P$, Chandiramani K. Positive and negative subtypes of schizophrenia. A follow-up study from India. Schizophr Res. 1990;3(2):107-116. doi:10.1016/0920-9964(90)90043-7
18. Lindenmayer J-P, Kay SR, Friedman C. Negative and positive schizophrenic syndromes after the acute phase: a prospective follow-up. Compr Psychiatry. 1986;27(4):276-286. doi:10.1016/ 0010-440X(86)90003-9

19. Pogue-Geile MF, Harrow M. Negative symptoms in schizophrenia: their longitudinal course and prognostic importance. Schizophr Bull. 1985;11(3):427-439. doi:10.1093/schbul/11.3.427

20. Thara R, Henrietta M, Joseph A, Rajkumar S, Eaton WW. Ten-year course of schizophrenia-the Madras longitudinal study. Acta Psychiatr Scand. 1994;90(5):329-336. doi:10.1111/j.1600-0447.1994.tb01602.x

21. Bobes J, Arango C, Garcia-Garcia M, Rejas J, CLAMORS Study Collaborative Group. Prevalence of negative symptoms in outpatients with schizophrenia spectrum disorders treated with antipsychotics in routine clinical practice: findings from the CLAMORS study. J Clin Psychiatry. 2010;71(3):280-286. doi:10.4088/ JCP. $08 \mathrm{~m} 04250 \mathrm{yel}$

22. Rabinowitz J, Werbeloff N, Caers I, et al. Negative symptoms in schizophrenia-the remarkable impact of inclusion definitions in clinical trials and their consequences. Schizophr Res. 2013;150(23):334-338. doi:10.1016/j.schres.2013.06.023

23. Makinen J, Miettunen J, Isohanni M, Koponen H. Negative symptoms in schizophrenia: a review. Nord J Psychiatry. 2008;62 (5):334-341. doi:10.1080/08039480801959307

24. Rabinowitz J, Berardo CG, Bugarski-Kirola D, Marder S. Association of prominent positive and prominent negative symptoms and functional health, well-being, healthcare-related quality of life and family burden: a CATIE analysis. Schizophr Res. 2013;150(2-3):339-342. doi:10.1016/j.schres.2013.07.014

25. Foussias G, Agid O, Fervaha G, Remington G. Negative symptoms of schizophrenia: clinical features, relevance to real world functioning and specificity versus other CNS disorders. Eur Neuropsychopharmacol. 2014;24(5):693-709. doi:10.1016/j.euroneuro.2013.10.017

26. Millan MJ, Fone K, Steckler T, Horan WP. Negative symptoms of schizophrenia: clinical characteristics, pathophysiological substrates, experimental models and prospects for improved treatment. Eur Neuropsychopharmacol. 2014;24(5):645-692. doi:10.1016/j.euroneuro.2014.03.008

27. Marder SR, Galderisi S. The current conceptualization of negative symptoms in schizophrenia. World Psychiatry. 2017;16(1):14-24. doi: $10.1002 /$ wps. 20385

28. Harvey PD, Strassnig M. Predicting the severity of everyday functional disability in people with schizophrenia: cognitive deficits, functional capacity, symptoms, and health status. World Psychiatry. 2012;11(2):73-79. doi:10.1016/j.wpsyc.2012.05.004

29. Malaspina D, Walsh-Messinger J, Gaebel W, et al. Negative symptoms, past and present: a historical perspective and moving to DSM-5. Eur Neuropsychopharmacol. 2014;24(5):710-724. doi:10. 1016/j.euroneuro.2013.10.018

30. Abi-Dargham A. Do we still believe in the dopamine hypothesis? New data bring new evidence. Int $J$ Neuropsychopharmacol. 2004;7(Supplement 1):S1-S5. doi:10.1017/S1461145704004110

31. Stahl S. Stahl's Essential Psychopharmacology: Neuroscientific Basis and Practical Application. 4th ed. Cambridge; New York: Cambridge University Press; 2013.

32. McCutcheon RA, Abi-Dargham A, Howes OD. Schizophrenia, dopamine and the striatum: from biology to symptoms. Trends Neurosci. 2019;42(3):205-220. doi:10.1016/j.tins.2018. 12.004

33. Gyertyán I, Saghy K, Laszy J, et al. Subnanomolar dopamine D3 receptor antagonism coupled to moderate D2 affinity results in favourable antipsychotic-like activity in rodent models: II. Behavioural characterisation of RG-15. Naunyn Schmiedebergs Arch Pharmacol. 2008;378(5):529-539. doi:10.1007/s00210-008-0311-x

34. Joyce JN, Millan MJ. Dopamine D3 receptor antagonists as therapeutic agents. Drug Discov Today. 2005;10(13):917-925. doi:10. 1016/S1359-6446(05)03491-4 
35. Kiss B, Laszlovszky I, Horvath A, et al. Subnanomolar dopamine D3 receptor antagonism coupled to moderate D2 affinity results in favourable antipsychotic-like activity in rodent models: I. Neurochemical characterisation of RG-15. Naunyn Schmiedebergs Arch Pharmacol. 2008;378(5):515-528. doi:10.1007/s00210-008-0308-5

36. Laszy J, Laszlovszky I, Gyertyán I. Dopamine D3 receptor antagonists improve the learning performance in memory-impaired rats. Psychopharmacology (Berl). 2005;179(3):567-575. doi:10.1007/ s00213-004-2096-z

37. Leggio GM, Salomone S, Bucolo C, et al. Dopamine D(3) receptor as a new pharmacological target for the treatment of depression. Eur J Pharmacol. 2013;719(1-3):25-33. doi:10.1016/j.ejphar.2013. 07.022

38. Duric V, Banasr M, Franklin T, et al. Cariprazine exhibits anxiolytic and dopamine $\mathrm{d} 3$ receptor-dependent antidepressant effects in the chronic stress model. Int J Neuropsychopharmacol. 2017;20 (10):788-796. doi:10.1093/ijnp/pyx038

39. Watson DJ, Loiseau F, Ingallinesi M, Millan MJ, Marsden CA, Fone KC. Selective blockade of dopamine D3 receptors enhances while D2 receptor antagonism impairs social novelty discrimination and novel object recognition in rats: a key role for the prefrontal cortex. Neuropsychopharmacology. 2012;37(3):770-786. doi:10.1038/npp.2011.254

40. Zimnisky R, Chang G, Gyertyán I, Kiss B, Adham N, Schmauss C. Cariprazine, a dopamine $\mathrm{D}(3)$-receptor-preferring partial agonist, blocks phencyclidine-induced impairments of working memory, attention set-shifting, and recognition memory in the mouse. Psychopharmacology (Berl). 2013;226(1):91-100. doi:10.1007/ s00213-012-2896-5

41. Lacroix LP, Hows ME, Shah AJ, Hagan JJ, Heidbreder CA. Selective antagonism at dopamine D3 receptors enhances monoaminergic and cholinergic neurotransmission in the rat anterior cingulate cortex. Neuropsychopharmacology. 2003;28(5):839-849. doi:10.1038/sj.npp.1300114

42. Sokoloff P, Le Foll B. The dopamine D3 receptor, a quarter century later. Eur J Neurosci. 2017;45(1):2-19. doi:10.1111/ejn.13390

43. Joseph JD, Wang YM, Miles PR, et al. Dopamine autoreceptor regulation of release and uptake in mouse brain slices in the absence of $\mathrm{D}(3)$ receptors. Neuroscience. 2002;112(1):39-49. doi:10.1016/S0306-4522(02)00067-2

44. Koeltzow TE, Xu M, Cooper DC, et al. Alterations in dopamine release but not dopamine autoreceptor function in dopamine D3 receptor mutant mice. J Neurosci. 1998;18(6):2231-2238. doi:10. 1523/JNEUROSCI.18-06-02231.1998

45. Le Foll B, Diaz J, Sokoloff P. Neuroadaptations to hyperdopaminergia in dopamine D3 receptor-deficient mice. Life Sci. 2005;76:1281-1296. doi:10.1016/j.1fs.2004.09.018

46. Gorwood P. Neurobiological mechanisms of anhedonia. Dialogues Clin Neurosci. 2008;10(3):291-299.

47. Stahl SM. Drugs for psychosis and mood: unique actions at D3, D2, and D1 dopamine receptor subtypes. CNS Spectr. 2017;22 (5):375-384. doi:10.1017/S1092852917000608

48. Clarkson RL, Liptak AT, Gee SM, Sohal VS, Bender KJ. D3 receptors regulate excitability in a unique class of prefrontal pyramidal cells. J Neurosci. 2017;37(24):5846-5860. doi:10.1523/ JNEUROSCI.0310-17.2017

49. Yang S, Ben-Shalom R, Ahn M, et al. beta-arrestin-dependent dopaminergic regulation of calcium channel activity in the axon initial segment. Cell Rep. 2016;16(6):1518-1526. doi:10.1016/j. celrep.2016.06.098

50. D’Amico AG, Scuderi S, Leggio GM, Castorina A, Drago F, D'Agata V. Increased hippocampal CREB phosphorylation in dopamine D3 receptor knockout mice following passive avoidance conditioning. Neurochem Res. 2013;38(12):2516-2523. doi:10.100 7/s11064-013-1164-3
51. Lemercier CE, Schulz SB, Heidmann KE, Kovacs R, Gerevich Z. Dopamine D3 receptors inhibit hippocampal gamma oscillations by disturbing CA3 pyramidal cell firing synchrony. Front Pharmacol. 2015;6:297.

52. Coyle JT. NMDA receptor and schizophrenia: a brief history. Schizophr Bull. 2012;38(5):920-926. doi:10.1093/schbul/sbs076

53. Domino EF, Mirzoyan D, Tsukada H. N-methyl-D-aspartate antagonists as drug models of schizophrenia: a surprising link to tobacco smoking. Prog Neuropsychopharmacol Biol Psychiatry. 2004;28(5):801-811. doi:10.1016/j.pnpbp.2004.05.024

54. Goff DC, Coyle JT. The emerging role of glutamate in the pathophysiology and treatment of schizophrenia. Am J Psychiatry. 2001;158(9):1367-1377. doi:10.1176/appi.ajp.158.9.1367

55. Heresco-Levy U, Javitt DC. Comparative effects of glycine and D-cycloserine on persistent negative symptoms in schizophrenia: a retrospective analysis. Schizophr Res. 2004;66(2-3):89-96. doi:10.1016/S0920-9964(03)00129-4

56. Javitt DC, Zylberman I, Zukin SR, Heresco-Levy U, Lindenmayer JP. Amelioration of negative symptoms in schizophrenia by glycine. Am J Psychiatry. 1994;151(8):1234-1236.

57. Buchanan RW, Javitt DC, Marder SR, et al. The Cognitive and Negative Symptoms in Schizophrenia Trial (CONSIST): the efficacy of glutamatergic agents for negative symptoms and cognitive impairments. Am J Psychiatry. 2007;164(10):1593-1602. doi:10.11 76/appi.ajp.2007.06081358

58. Coyle JT. Glutamate and schizophrenia: beyond the dopamine hypothesis. Cell Mol Neurobiol. 2006;26(4-6):365-384. doi:10.100 7/s10571-006-9062-8

59. Chue P, Lalonde JK. Addressing the unmet needs of patients with persistent negative symptoms of schizophrenia: emerging pharmacological treatment options. Neuropsychiatr Dis Treat. 2014; 10:777-789. doi:10.2147/NDT

60. Leriche L, Diaz J, Sokoloff P. Dopamine and glutamate dysfunctions in schizophrenia: role of the dopamine D3 receptor. Neurotox Res. 2004;6(1):63-71. doi:10.1007/BF03033298

61. Kirkpatrick B, Fenton WS, Carpenter WT Jr., Marder SR. The NIMH-MATRICS consensus statement on negative symptoms. Schizophr Bull. 2006;32(2):214-219. doi:10.1093/schbul/sb j053

62. Kirkpatrick B, Fischer B. Subdomains within the negative symptoms of schizophrenia: commentary. Schizophr Bull. 2006;32 (2):246-249. doi:10.1093/schbul/sbj054

63. Messinger JW, Tremeau F, Antonius D, et al. Avolition and expressive deficits capture negative symptom phenomenology: implications for DSM-5 and schizophrenia research. Clin Psychol Rev. 2011;31(1):161-168. doi:10.1016/j.cpr.2010.09.002

64. APA. Diagnostic and Statistical Manual of Mental Disorders. 5th ed. Arlington, VA: American Psychiatric Association; 2013.

65. Kay SR, Fiszbein A, Opler LA. The Positive and Negative Syndrome Scale (PANSS) for schizophrenia. Schizophr Bull. 1987;13(2):261-276. doi:10.1093/schbul/13.2.261

66. Andreasen NC. The Scale for the Assessment of Negative Symptoms (SANS): conceptual and theoretical foundations. $\mathrm{Br}$ J Psychiatry Suppl. 1989;155(7):49-58. doi:10.1192/S000712500 0291496

67. Axelrod BN, Goldman RS, Alphs LD. Validation of the 16-item Negative Symptom Assessment. J Psychiatr Res. 1993;27 (3):253-258. doi:10.1016/0022-3956(93)90036-2

68. Kring AM, Gur RE, Blanchard JJ, Horan WP, Reise SP. The Clinical Assessment Interview for Negative Symptoms (CAINS): final development and validation. Am J Psychiatry. 2013;170 (2):165-172. doi:10.1176/appi.ajp.2012.12010109

69. Kirkpatrick B, Strauss GP, Nguyen L, et al. The brief negative symptom scale: psychometric properties. Schizophr Bull. 2011;37 (2):300-305. doi:10.1093/schbul/sbq059 
70. Daniel DG. Issues in selection of instruments to measure negative symptoms. Schizophr Res. 2013;150(2-3):343-345. doi:10.1016/j. schres.2013.07.005

71. Alphs L, Morlock R, Coon C, van Willigenburg A, Panagides J. The 4-item Negative Symptom Assessment (NSA-4) instrument: a simple tool for evaluating negative symptoms in schizophrenia following brief training. Psychiatry (Edgmont). 2010;7(7):26-32.

72. Velligan DI, Lopez L, Castillo DA, Manaugh B, Milam AC, Miller AL. Interrater reliability of using brief standardized outcome measures in a community mental health setting. Psychiatr Serv. 2011;62(5):558-560. doi:10.1176/ps.62.5.pss6205_0558

73. Firth J, Torous J. Smartphone apps for schizophrenia: a systematic review. JMIR Mhealth Uhealth. 2015;3(4):e102. doi:10.2196/ mhealth. 4930

74. Haddad PM, Correll CU. The acute efficacy of antipsychotics in schizophrenia: a review of recent meta-analyses. Ther Adv Psychopharmacol. 2018;8(11):303-318. doi:10.1177/20451253187 81475

75. Leucht S, Tardy M, Komossa K, Heres S, Kissling W, Davis JM. Maintenance treatment with antipsychotic drugs for schizophrenia. Cochrane Database Syst Rev. 2012;(5):CD008016.

76. Aleman A, Lincoln TM, Bruggeman R, et al. Treatment of negative symptoms: where do we stand, and where do we go? Schizophr Res. 2017;186:55-62. doi:10.1016/j.schres.2016.05. 015

77. Barnes TR, Schizophrenia Consensus Group of British Association for P. Evidence-based guidelines for the pharmacological treatment of schizophrenia: recommendations from the British Association for Psychopharmacology. J Psychopharmacol. 2011;25(5):567-6 20. doi:10.1177/0269881110391123

78. Fusar-Poli P, Papanastasiou E, Stahl D, et al. Treatments of negative symptoms in schizophrenia: meta-analysis of 168 randomized placebo-controlled trials. Schizophr Bull. 2015;41(4):892-899. doi: $10.1093 /$ schbul/sbu 170

79. Leucht S, Leucht $C$, Huhn $M$, et al. Sixty years of placebo-controlled antipsychotic drug trials in acute schizophrenia: systematic review, bayesian meta-analysis, and meta-regression of efficacy predictors. Am J Psychiatry. 2017;174(10):927-942. doi:10.1176/appi.ajp.2017.16121358

80. Leucht S, Arbter D, Engel RR, Kissling W, Davis JM. How effective are second-generation antipsychotic drugs? A meta-analysis of placebo-controlled trials. Mol Psychiatry. 2009; 14(4):429-447. doi:10.1038/sj.mp.4002136

81. Leucht S, Corves C, Arbter D, Engel RR, Li C, Davis JM. Secondgeneration versus first-generation antipsychotic drugs for schizophrenia: a meta-analysis. Lancet. 2009;373(9657):31-41. doi:10.1016/S01406736(08)61764-X

82. Krause M, Zhu Y, Huhn M, et al. Antipsychotic drugs for patients with schizophrenia and predominant or prominent negative symptoms: a systematic review and meta-analysis. Eur Arch Psychiatry Clin Neurosci. 2018;268:625-639. doi:10.1007/s00406-018-0869-3

83. Németh G, Laszlovszky I, Czobor P, et al. Cariprazine versus risperidone monotherapy for treatment of predominant negative symptoms in patients with schizophrenia: a randomised, double-blind, controlled trial. Lancet. 2017;389(10074):11 03-1113. doi:10.1016/S0140-6736(17)30060-0

84. Cho DI, Zheng M, Kim KM. Current perspectives on the selective regulation of dopamine $\mathrm{D}(2)$ and $\mathrm{D}(3)$ receptors. Arch Pharm Res. 2010;33(10):1521-1538. doi:10.1007/s12272-010-1005-8

85. Guy W. Clinical global impressions. In: Guy W, editor. ECDEU Assessment Manual for Psychopharmacology: Publication ADM 76-338. Rockville, MD: National Institute of Mental Health, Psychopharmacology Research Branch; 1976:217-222.
86. Morosini PL, Magliano L, Brambilla L, Ugolini S, Pioli R. Development, reliability and acceptability of a new version of the DSM-IV Social and Occupational Functioning Assessment Scale (SOFAS) to assess routine social functioning. Acta Psychiatr Scand. 2000;101(4):323-329.

87. Arango C, Garibaldi G, Marder SR. Pharmacological approaches to treating negative symptoms: a review of clinical trials. Schizophr Res. 2013;150(2-3):346-352. doi:10.1016/j.schres.2013.07.026

88. Correll CU, Rubio JM, Inczedy-Farkas G, Birnbaum ML, Kane JM, Leucht S. Efficacy of 42 pharmacologic cotreatment strategies added to antipsychotic monotherapy in schizophrenia: systematic overview and quality appraisal of the meta-analytic evidence. JAMA Psychiatry. 2017;74(7):675-684. doi:10.1001/ jamapsychiatry.2017.0624

89. Galling B, Vernon JA, Pagsberg AK, et al. Efficacy and safety of antidepressant augmentation of continued antipsychotic treatment in patients with schizophrenia. Acta Psychiatr Scand. 2018;137 (3):187-205. doi:10.1111/acps.2018.137.issue-3

90. Helfer B, Samara MT, Huhn M, et al. Efficacy and safety of antidepressants added to antipsychotics for schizophrenia: a systematic review and meta-analysis. Am J Psychiatry. 2016;173(9):876-886. doi:10.1176/appi.ajp.2016.15081035

91. Torrey EF, Davis JM. Adjunct treatments for schizophrenia and bipolar disorder: what to try when you are out of ideas. Clin Schizophr Relat Psychoses. 2012;5(4):208-216. doi:10.3371/CSRP.5.4.5

92. Davidson M, Saoud J, Staner C, et al. Efficacy and safety of MIN-101: a 12-week randomized, double-blind, placebo-controlled trial of a new drug in development for the treatment of negative symptoms in schizophrenia. Am J Psychiatry. 2017;174 (12):1195-1202. doi:10.1176/appi.ajp.2017.17010122

93. Micoulaud Franchi JA, Quiles C, Belzeaux R, Adida M, Azorin JM. Negative symptoms of schizophrenia: from electrophysiology to electrotherapy. Encephale. 2015;41(6Suppl 1):6S50S56. doi:10.1016/S0013-7006(16)30011-2

94. Krogmann A, Peters L, von Hardenberg L, Bödeker K, Nöhles VB, Correll CU. Keeping up with the therapeutic advances in schizophrenia: a review of novel and emerging pharmacological entities. CNS Spectr. 2019;24(S1):38-69. doi:10.1017/S109285291900124X

95. Beck AT, Grant PM, Huh GA, Perivoliotis D, Chang NA. Dysfunctional attitudes and expectancies in deficit syndrome schizophrenia. Schizophr Bull. 2013;39(1):43-51. doi:10.1093/ schbul/sbr040

96. Chacon F, Mora F, Gervas-Rios A, Gilaberte I. Efficacy of lifestyle interventions in physical health management of patients with severe mental illness. Ann Gen Psychiatry. 2011;10:22. doi:10.1186/1744859X-10-22

97. Turner DT, van der Gaag M, Karyotaki E, Cuijpers P. Psychological interventions for psychosis: a meta-analysis of comparative outcome studies. Am J Psychiatry. 2014;171(5):523-538. doi:10.1176/appi.ajp.2013.13081159

98. Elis O, Caponigro JM, Kring AM. Psychosocial treatments for negative symptoms in schizophrenia: current practices and future directions. Clin Psychol Rev. 2013;33(8):914-928. doi:10.1016/j. cpr.2013.07.001

99. Wykes T, Huddy V, Cellard C, McGurk SR, Czobor P. A meta-analysis of cognitive remediation for schizophrenia: methodology and effect sizes. Am J Psychiatry. 2011;168(5):472-485. doi:10.1176/appi.ajp.2010.10060855

100. Jauhar S, McKenna PJ, Radua J, Fung E, Salvador R, Laws KR. Cognitive-behavioural therapy for the symptoms of schizophrenia: systematic review and meta-analysis with examination of potential bias. Br J Psychiatry. 2014;204(1):20-29. doi:10.1192/bjp.bp.11 2.116285 
101. Klingberg S, Wolwer W, Engel C, et al. Negative symptoms of schizophrenia as primary target of cognitive behavioral therapy: results of the randomized clinical TONES study. Schizophr Bull. 2011;37(Suppl 2):S98-110. doi:10.1093/schbul/sbr073

102. Velligan D, Maples N, Roberts DL, Medellin EM. Integrated psychosocial treatment for negative symptoms. Am J Psychiatric Rehab. 2014;17(1):1-19. doi:10.1080/15487768.2013.873370
103. Velligan DI, Roberts D, Mintz J, et al. A randomized pilot study of MOtiVation and Enhancement (MOVE) training for negative symptoms in schizophrenia. Schizophr Res. 2015;165(2-3):175-180. doi:10.1016/j.schres.2015.04.008

\section{Publish your work in this journal}

Neuropsychiatric Disease and Treatment is an international, peerreviewed journal of clinical therapeutics and pharmacology focusing on concise rapid reporting of clinical or pre-clinical studies on a range of neuropsychiatric and neurological disorders. This journal is indexed on PubMed Central, the 'PsycINFO' database and CAS, and is the official journal of The International Neuropsychiatric Association (INA). The manuscript management system is completely online and includes a very quick and fair peer-review system, which is all easy to use. Visit http://www.dovepress.com/testimonials.php to read real quotes from published authors.

Submit your manuscript here: https://www.dovepress.com/neuropsychiatric-disease-and-treatment-journal 